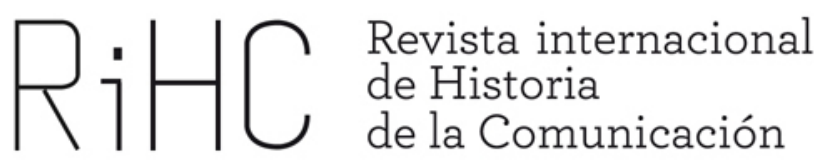

\title{
NACIMIENTO Y EVOLUCIÓN DE LA PRENSA EN FILIPINAS EN EL SIGLO XIX: DE LOS INTERESES ESPAÑOLES AL NACIONALISMO FILIPINO
}

Birth and Evolution of the Press in the Nineteenth Century Philippines: from Spanish Interests to Filipino Nationalism

DOI: http://dx.doi.org/10.12795/RiHC.2017.i08.01

Carlos Isabel

Universidad de Waseda (Japón)

carlos.isabel@aoni.waseda.jp

aceptado: $15-2-2017$

recibido: $12-5-2017$

Resumen: En este trabajo se hace una aproximación histórica a la escena periodística que surgió en Filipinas en el siglo XIX: cómo nació y cómo se diversificó, qué problemas afrontó, qué tipos de publicaciones aparecieron y cómo se utilizó la prensa con fines políticos por parte de los nacionalistas filipinos a finales de siglo. Se destaca que a pesar de la multitud de lenguas que se hablaban en Filipinas, el español es casi la única lengua utilizada por la prensa del siglo XIX.

Palabras clave: Filipinas, siglo XIX, periodismo colonial, español 
Abstract: This paper lays out a historical introduction to the press in the Philippines in the $19^{\text {th }}$ century. It examines its birth, development, how it diversified, the problems it had to face, the types of press that came into existence, and the use of the press as political weapon against Spanish rule by the Filipino nationalists towards the end of the century. The preponderance of Spanish as the language of the press is also outlined.

Keywords: Philippines, $19^{\text {th }}$ century, colonial journalism, Spanish

\section{Introducción}

En la introducción a su trabajo sobre la prensa filipina en español en las primeras cuatro décadas del siglo XX, Checa Godoy afirmaba que "es una página poco conocida y poco aprendida del periodismo en español" (2015, p.23). A la vista de la escasez, casi inexistencia, de estudios publicados sobre la prensa filipina en el siglo XIX, podríamos decir que la misma afirmación es aplicable al siglo XIX, el que vio el nacimiento de la prensa en el archipiélago filipino bajo administración española.

El presente trabajo tiene como objetivo describir y analizar esta otra etapa igualmente desconocida de la historia de la prensa filipina, que como veremos utilizó casi en exclusiva la lengua castellana. Nos detendremos en los primeros noticieros escritos, que datan de los años 1810 y 1820, para continuar con una descripción de la evolución que siguió el panorama periodístico hasta la pérdida de la soberanía española en 1898. Si bien sería posible acotar periodos más cortos, y siendo conscientes de la dificultad de profundizar al enfrentarnos a nada menos que nueve décadas con las limitaciones de espacio que fija un artículo, hemos decidido abarcar todo el siglo XIX por dos razones principales: por un lado la novedad del tema y el carácter introductorio que pretende tener este trabajo, y por otro lado la ausencia de eventos históricos que afectasen de manera importante a la evolución de la prensa dentro del siglo XIX filipino y que justifiquen su utilización para el establecimiento de límites temporales. Dejamos a futuras investigaciones la posibilidad de profundizar en aspectos más concretos de la prensa filipina del XIX, por ejemplo, analizando más detalladamente algún género periodístico, describiendo pormenorizadamente la trayectoria de algún periódico, periodista o editor, o mostrando el reflejo que algún evento histórico o cambio social o político pudo tener en la prensa, entre otras muchas posibilidades. También descartamos por ahora, por exceder los límites y posibilidades de este artículo, realizar un estudio comparativo, que sin duda sería interesante de llevar a cabo tanto con la prensa decimonónica de la España peninsular como con la de otros territorios coloniales del Sudeste Asiático.

Con el crecimiento de la comunidad española y la actividad económica, la sociedad manilense del siglo XIX se desarrolló y aumentó su demanda de información y entretenimiento, ante lo cual surgieron multitud de periódicos y revistas de diferente 
índole. En los comienzos la difusión de noticias impresas se limitaba a hojas informativas distribuidas en momentos puntuales, pero la oferta, la calidad y la regularidad de las publicaciones fue aumentando y en las últimas décadas la actividad periodística alcanzó grandes cotas de desarrollo. Se han contabilizado alrededor de 170 periódicos y revistas aparecidos a lo largo del siglo, aunque la mayoría tuvieron una vida efímera, debido a menudo a problemas financieros. Siempre pendiente de España, la prensa filipina reprodujo los enfrentamientos ideológicos que se dieron en la metrópoli, e informó puntualmente de cuantos eventos internacionales pudieran afectar tanto a España como a su provincia filipina.

\section{Fuentes disponibles y metodología}

Fue muy escasa la atención prestada a Filipinas -y casi nula a los otros archipiélagos del Océano Pacífico que formaron parte del Imperio Español- tras la pérdida de la soberanía en 1898. En las últimas décadas del siglo XX hubo un auge en los estudios filipinistas que se ha mantenido hasta la actualidad, aunque sin dejar nunca de ser un tema menor desde el punto de vista cuantitativo en la historiografía española ${ }^{1}$. El ámbito concreto del periodismo filipino en el siglo XIX ha seguido esta misma tendencia, con muy pocos trabajos dedicados al mismo, tanto en España como en Filipinas y EEUU.

La mayoría de los trabajos posteriores, y también el presente, se basa en los catálogos realizados por Wenceslao Retana -el libro titulado El periodismo filipino (1895) y el apartado de igual título en el volumen III de su Aparato Bibliográfico (1906)- y en menor medida en el de Artigas y Cuerva (1909). Estos tres trabajos son catalogaciones cronológicas comentadas de los periódicos que fueron apareciendo a lo largo del siglo XIX. El de 1895 de Retana está basado en su colección personal y su experiencia en Filipinas, y el que publicó en 1906 es una ampliación del anterior completada a su regreso a España con los fondos de la biblioteca de la Compañía General de Tabacos de Filipinas. En España se pueden encontrar fondos de prensa filipina del siglo XIX en la Biblioteca Nacional, aunque la consulta de periódicos para este trabajo se realizó en la hemeroteca de la Biblioteca Rizal, en la Universidad Ateneo de Manila. En el siglo XX se publicaron algunos trabajos en Filipinas, también en forma de catálogos, pero menos estructurados y exhaustivos que los de Retana y Artigas y Cuerva. Nos referimos a las monografías autopublicadas de Taylor (1927) y de Valenzuela (1933), y al artículo de Fernandez publicado en la revista Philippine Studies en 1989, titulado "The Philippine

\footnotetext{
${ }^{1}$ Puede encontrarse un análisis pormenorizado de este auge en los estudios filipinistas en el artículo de Alonso Álvarez e Hidalgo Nuchera, "Los nietos de Legazpi revisan el pasado". Incluye el recuento de los trabajos académicos publicados, organizados por temas, épocas de estudio y tipo de publicación.
} 
Press System: 1811-1989" pero centrado en el siglo XX y dedicando apenas unas páginas introductorias a los primeros y los últimos periódicos del siglo XIX. El breve trabajo de Taylor sí que cubre todo el siglo XIX, y muy sucintamente los comienzos del $X X$. Cita únicamente a Retana y consta de una sucesión de datos y traducciones al inglés de extractos de Retana y de algunos periódicos, sin análisis de la evolución del panorama periodístico filipino. En el caso de Valenzuela, su obra es más extensa y ofrece mucha más información, pero no apreciamos diferencias de tipo cualitativo con respecto al artículo de Taylor. En 1955 Sabido Aguirre presentó su tesis doctoral en la Universidad Complutense de Madrid, con un catálogo muy similar al de Valenzuela, aunque más exhaustivo y con la aportación de alguna información novedosa, por ejemplo, sobre los periódicos chinos o las publicaciones estudiantiles. En tiempos más recientes, las investigadoras españolas Rosa Cal $(1998,1999)$ y Gloria Cano $(2011)$ han publicado varios trabajos, referidos en la bibliografía, dedicados a la prensa filipina del siglo XIX. En ellos analizan el ejercicio de la censura de prensa y el papel que jugaron ciertos periódicos, por ejemplo La Solidaridad, en el movimiento nacionalista que condujo a la revolución en 1896 y la consecuente pérdida de la soberanía española en Filipinas. Son trabajos muy valiosos, pero no permiten apreciar la evolución del fenómeno periodístico desde su nacimiento, sencillamente porque no era ése su objetivo.

\section{Contexto histórico y sociolingüístico}

Ya desde antes de la llegada de los españoles los habitantes del archipiélago filipino habían tenido contactos con culturas muy diferentes: comerciantes árabes y chinos, viajeros indios y de otras áreas del Sudeste Asiático, incluso exploradores portugueses alrededor de las Islas Molucas. Estas relaciones trajeron diversos productos, ideas, religiones y costumbres. La recepción de variadas influencias culturales continuó y se potenció con las rutas marítimas comerciales que España creó alrededor de Filipinas; el galeón que conectaba regularmente Manila con Acapulco y las rutas de distribución derivadas a otros puntos de Asia. El interés comercial que fue adquiriendo el puerto de Manila atrajo a personas de muchos lugares del mundo. En palabras de GarcíaAbásolo:

"El abigarramiento étnico de la ciudad la convirtió en la más exótica del dominio colonial español en su conjunto. Probablemente fue uno de los experimentos más originales de convivencia multiétnica en el ámbito conocido por los europeos: en Manila había, entre otros, filipinos, chinos, japoneses, indios, armenios, españoles europeos y españoles americanos, indígenas americanos y negros" (2011: 233-234). 
Este cosmopolitismo de la ciudad conocida como "La Perla de Oriente", así como su actividad comercial, llegó a su esplendor en el siglo XIX, época que también vio un aumento importante de la hasta entonces exigua inmigración de españoles peninsulares. Esta circunstancia, en conjunción con la apertura del Canal de Suez y los adelantos tecnológicos de los transportes y las comunicaciones (el barco a vapor, el ferrocarril, el telégrafo, etcétera) pudieron favorecer el surgimiento del periodismo en Filipinas. La existencia de una tradición de imprenta de libros que se remonta a comienzos del siglo XVII pudo ser otro factor positivo.

De todos modos, en este siglo los españoles siguieron siendo una ínfima minoría de la población total del archipiélago. La ausencia de censos fiables hace difícil manejar datos poblacionales exactos, pero las fuentes disponibles guardan cierta consistencia. Por ejemplo, Ortiz Armengol (2000: 300-301), refiriéndose a cálculos hechos en 1837, habla de “...una población de unos tres millones de naturales del país, más unos doscientos mil chino-filipinos y los seis mil españoles -peninsulares, criollos, mestizos de sangre española-...", y según González Rodríguez (1877: 33-34), "El recuento oficial verificado de 1858 ofrece, contando con la existencia de unos 6000 europeos, un cómputo total de población que se eleva a cuatro millones trescientas mil almas" ${ }^{2}$. Además, la mayoría de los españoles residía en Manila y en menor medida en las ciudades de Cebú e Iloilo, en las que se centró la publicación de periódicos. En las zonas más remotas, a menudo el único español residente en cada pueblo era el párroco o misionero. A pesar de la prolongada administración española y de los esfuerzos legislativos y educativos, el número de filipinos que manejasen el idioma español fue siempre reducido, especialmente en las zonas más alejadas de los núcleos de población española, y esto limitó la difusión de la prensa, casi toda escrita en español.

En Malasia y en Indonesia los respectivos primeros periódicos son anteriores al primero en Filipinas, pero fijándonos en el número de publicaciones, y a falta de realizarse un estudio comparativo que tome varios factores en consideración, parece que la escena periodística en Filipinas no fue menos activa que la de estas otras colonias europeas de la época en el Sudeste Asiático. En Malasia Británica publicaron su primer periódico en 1806, y a lo largo del siglo XIX aparecieron alrededor de cuarenta publicaciones periodísticas ${ }^{3}$. En el caso de las Indias Orientales Neerlandesas, el primer periódico, Bataviasche Nouvelles, se publicó en 1744, y las obras consultadas contabilizan entre treinta y cincuenta periódicos tanto a mediados como a finales del

\footnotetext{
${ }^{2}$ Puesto que es conocida la presencia de europeos no españoles en Filipinas en aquella época, no podemos suponer que estos 6000 fueran españoles.

${ }^{3}$ Diferentes fuentes señalan The Prince of Wales Island Gazette o Government Gazette como el primer periódico editado en Malasia, pero en ambos casos el año de publicación es 1806, en Penang. El número de publicaciones malayas del siglo XIX está tomado de OTHMAN, M.D. (1992): "Malaysian Press: A brief account of newspaper published in British Malaya" en Jurnal Komunikasi, 8, pp. 117-130.
} 
siglo XIX ${ }^{4}$. Moya y Jiménez, militar español destinado en Filipinas que describió el estado de las islas en 1882 , señaló la ventaja de la prensa filipina sobre la de las otras colonias europeas vecinas, aunque sin proporcionar datos ni detalles que sustenten su afirmación: "Si una de las manifestaciones más patentes de la cultura de un país es la historia de su prensa periódica, las Islas Filipinas llevan, en este concepto, la delantera a todas las posesiones europeas en la Oceanía, no obstante las condiciones excepcionales por que ha atravesado desde su nacimiento" (1883: 216).

\section{Las primeras noticias escritas}

El pionero de la imprenta filipina Tomás Pinpin publicó en 1637 lo que podría considerarse la primera publicación de corte periodístico de Filipinas, titulada Sucesos Felices y consistente en catorce páginas con partes de guerra (Fernandez, 1989: 318). Sin embargo, casi todos los trabajos dedicados a la historia del periodismo en Filipinas señalan que los orígenes están en las llamadas "Hojas Volantes", hojas informativas impresas que aparecían de manera irregular, cuando llegaban noticias importantes de España o para informar de la llegada de barcos. Se repartían por la calle y corrían de mano en mano, o se colgaban en algún lugar concurrido, bajo el título Al Público, Aviso, o Aviso al Público. Carecían de firma, número de serie o datos de impresión. Hay menciones a su existencia desde finales del siglo XVIII, y siguieron apareciendo durante la primera década del siglo XIX.

Valenzuela señala que la primera apareció el 27 de febrero de 1779, con una noticia sobre el estado de la campaña bélica contra los piratas mahometanos en el archipiélago de Joló (1933: 13). En los años siguientes el tema más tratado sería la situación de España con respecto a Francia y la Guerra de Independencia, así como la situación política y militar en el resto de Europa, algo que naturalmente preocupaba mucho en las colonias españolas por las repercusiones que podían sufrir si España quedaba bajo dominio del Imperio Francés. En una carta fechada el 1 de marzo de 1895 y dirigida a Juan P. Criado y Domínguez, el filipinista Wenceslao Retana asegura haber encontrado en los meses anteriores informaciones sobre hojas volantes manuscritas. La existencia de este tipo de hojas volantes no se menciona en ninguna otra fuente de las consultadas para este trabajo. Esa carta aparece publicada en el preámbulo a la obra de Retana El periodismo filipino (1895), aunque nada se trata de esas hojas volantes en el cuerpo de la obra.

\footnotetext{
${ }^{4}$ Los datos de Indonesia corresponden a aproximaciones encontradas en EAMAN, R. (2009): Historical Dictionary of Journalism, Maryland, Scarecrow Press; CRIBB, R. (2000): Historical Atlas of Indonesia, Richmond, Curzon Press; ADAM, A.B. (1995): The vernacular press and the emergence of modern Indonesian consciousness: (1855-1913), Ithaca, N. Y., Cornell University.
} 
La primera publicación con datos de imprenta, numeraciones y firma de un editor fue Del Superior Gobierno. Apareció por primera vez el 8 de agosto de 1811. Fue la primera publicación periodística con intención de continuidad y regularidad, tras las "hojas volantes" y algunas traducciones de noticias de periódicos extranjeros que habían aparecido en 1809, aunque Del Superior Gobierno mantenía similitudes con las publicaciones anteriores: aparición con frecuencia irregular, distribución gratuita, número cambiante de páginas y contenidos que dependían de la disponibilidad de noticias llegadas del exterior y consideradas de interés general. El nombre puede deberse a que funcionaba como órgano de comunicación del gobierno colonial, para difundir noticias que consideraba que los ciudadanos debían conocer. De hecho, el editor era el propio gobernador general, D. Manuel Fernández de Folgueras. Según García de los Arcos (2000: 428), este gobernador fue también responsable de un Aviso al Público desde 1809, siendo ésta la única pista que hemos encontrado sobre la autoría de publicaciones informativas anteriores a 1811. Se publicaron quince números hasta el 7 de febrero de $1812^{5}$. En esta década tan solo apareció otra publicación con noticias, el 4 de julio de 1813, titulada Noticias sacadas de las gacetas de los sucesos acaecidos en la península en todo el año de 1812, que constaba de nueve páginas de noticias llegadas de Europa y solamente una página dedicada a noticias de Filipinas.

\section{Problemas para el desarrollo del periodismo}

A pesar de las condiciones favorables ya mencionadas, fueron varias las dificultades que afrontó el periodismo en Filipinas en este comienzo de andadura.

El primer obstáculo fue la censura. Retana señala que, salvo un breve periodo de libertad de imprenta entre 1813 y 1824, la censura se ejerció sobre la producción literaria y los periódicos durante todo el periodo de administración española de Filipinas, tanto para lo impreso en el archipiélago como para lo llegado del exterior (1907: 192). El estudio de Cal (1999), mucho más detallado, confirma esta perduración de la acción censora. De todos modos, según Moya y Jiménez, el rigor censor era variable (1882: 218-219). Cano lo confirma: "la censura de prensa [...] se atenuó dependiendo del ministro de Ultramar del momento" (2011: 172-173), y también apunta la posibilidad de que la propaganda antiespañola de las autoridades coloniales estadounidenses de comienzos del siglo XX exagerara la censura española, dejando una idea que ha pervivido hasta el presente:

\footnotetext{
${ }^{5}$ Para más información sobre Del Superior Gobierno y los contenidos de algunos de sus números, véase lo expuesto por Valenzuela (1933: 17-21).
} 
"La historiografía impuesta por los Estados Unidos se ha encargado de afirmar y difundir desde principios del siglo XX que durante el régimen colonial español existió una férrea censura, frente a la magnanimidad norteamericana que impulsó la libertad de prensa tras ocultar el archipiélago" (2011: 178-179).

La liberalización desarrollada en España por la ley de prensa de 1883 no llegó a Filipinas, donde la censura se mantuvo hasta el final de la administración española del archipiélago (Cal, 1999: 28). Existían dos tipos de censuras: la civil y la eclesiástica. En un principio eran aplicadas independientemente, pero debido al crecimiento del número de publicaciones, en 1856 se creó un único tribunal censor llamado Comisión permanente de censura, y compuesto por un presidente y ocho vocales, cuatro designados por el gobernador y cuatro por el arzobispo de Manila (Retana, 1907: 194). La preocupación principal de las autoridades era evitar la propagación de ideas "peligrosas" en Filipinas. Se pretendía que los contenidos periodísticos se limitaran a noticias y sucesos, evitando discursos ideológicos o políticos que pudieran favorecer el pensamiento subversivo y los movimientos anticoloniales ${ }^{6}$.

Existían también problemas relacionados con cuestiones materiales y profesionales que dificultaban el desarrollo del periodismo, como la escasez de buenas imprentas y de personal técnico, concretamente de cajistas. Por otro lado, los redactores en general no se dedicaban al periodismo de manera profesional, sino que tenían que dedicarse también a otras actividades para poder mantenerse económicamente, viéndose obligados muchos de ellos a dejar la actividad periodística en favor de otros negocios más lucrativos.

Por último, y también en relación con los problemas financieros, un grave problema era la baja cantidad de periódicos que se vendían, algo que dificultaba la viabilidad económica de muchos de los proyectos periodísticos que surgían ${ }^{7}$. Hasta 1889 no se vendieron periódicos y revistas en las calles sino tan solo por suscripción, y los frecuentes retrasos en los pagos por parte de los suscriptores eran otra fuente de estrecheces económicas para los responsables de las publicaciones ${ }^{8}$. Sin embargo, el escaso éxito de ventas no representa necesariamente un escaso éxito de público. Existía la costumbre de leer periódicos "de segunda mano", es decir, que el suscriptor que había comprado un ejemplar lo ponía en circulación tras haberlo leído, para que más personas aprovecharan su contenido. Según datos de Moya y Jiménez, en 1882

\footnotetext{
${ }^{6}$ En los últimos años del siglo se usó la prensa como medio de propaganda anticolonial e independentista, evitando la censura con la distribución ilegal de periódicos editados e impresos en el extranjero o en imprentas clandestinas en Filipinas.

${ }^{7}$ Los catálogos citados anteriormente incluyen la duración de cada publicación y a menudo explicaciones sobre la suerte que corrió, revelando que las dificultades económicas de promotores y redactores fue la causa de la prematura desaparición de muchas publicaciones, así como la falta de una correcta planificación.

${ }^{8}$ El primer periódico en venderse en las calles fue La Correspondencia de Manila (1889).
} 
había 3.500 personas suscriptoras de periódicos, pero unas 16.000 leían prensa regularmente (1883: 218$)^{9}$. Afortunadamente, estas dificultades no evitaron el desarrollo de una prensa abundante y variada, muestra de la complejidad que alcanzó la sociedad española en Filipinas en el siglo XIX y la riqueza de su vida cultural.

\section{El despegue}

Tras ocho años sin más material periodístico que algunas noticias extranjeras traducidas, el año 1821 es de gran importancia en la historia del periodismo filipino porque aparecen al menos seis publicaciones periodísticas: Ramillete Patriótico, El Filipino, Latigazo, El filipino noticioso, Noticioso filipino y La Filantropía (Retana, 1906: 1495-1507). Todos ellos eran semanarios o de aparición irregular, y publicados en Manila. A lo largo de todo el siglo XIX se dieron enfrentamientos entre periódicos que defendían distintas posiciones ideológicas y actitudes hacia las cuestiones coloniales, y según Taylor, ya comenzaron en estas primeras publicaciones de 1821 (1927: 8-9). Ramillete Patriótico era un semanario de corte liberal y constitucionalista, y algunos de los otros, como Latigazo, El Filipino y El filipino noticioso, surgieron como oposición impulsados por las fuerzas reaccionarias de Manila. En su número del 27 de mayo de 1821, Ramillete Patriótico denuncia la existencia de "cinco o seis publicaciones clandestinas" y llama a la acción de la justicia contra ellas. No hemos hallado más datos sobre tales publicaciones y desconocemos si se refiere a las mencionadas o a otras no catalogadas y también enfrentadas ideológicamente a Ramillete.

En las siguientes dos décadas aparecieron las Noticias compiladas de los papeles públicos de la Península (un único número en 1823), y los periódicos Registro Mercantil (1824), y Precios corrientes de Manila $(1839)^{10}$. Este último fue probablemente el primer periódico bilingüe de Filipinas, impreso a dos columnas en español y en inglés. Como se observa, en la década de 1830 tan solo hubo dos nuevas publicaciones, y ninguna a principios de los años 1840, pero a partir de 1843 los catálogos muestran la

\footnotetext{
${ }^{9}$ Resulta difícil calcular el porcentaje de personas alfabetizadas en esa época. Según datos posteriores, recogidos por las autoridades estadounidenses entre 1902 y 1903, el 44,5\% de la población sabía leer en algún idioma, y el 20,2\% sabía además escribir (Census of the Philippine Islands, 1903, vol. II, p.78). Puesto que el español era la lengua de instrucción en el sistema escolar público establecido en los años 1860 , es de suponer que una gran proporción estarían alfabetizados en español, aunque muchas escuelas religiosas siguieron alfabetizando en las lenguas filipinas.

${ }^{10}$ En el primer catálogo de Retana, de 1895, se mencionan El Filántropo (1822) y El Noticiero Filipino (¿1838?). No aparecen estas publicaciones en su segundo catálogo, de 1906, más completo y actualizado, por lo que pudieron ser errores cometidos por el propio autor y subsanados en su segundo trabajo.
} 
aparición de al menos un periódico al año hasta el fin de esta década. El uno de enero de 1847 apareció La Esperanza, primer periódico de frecuencia diaria ${ }^{11}$.

\section{Desarrollo y diversificación. Segunda mitad de siglo}

Por el número y diversidad de publicaciones aparecidas, fue en la segunda mitad del siglo XIX, y muy especialmente en las dos últimas décadas, cuando la prensa en Filipinas alcanzó un alto nivel de desarrollo. Para presentar las líneas en las que se produjo este florecimiento de la prensa vamos establecer cuatro categorías: prensa generalista surgida de la iniciativa privada, prensa oficial como órgano de comunicación de las autoridades administrativas, prensa dedicada a algún tema o público específico, prensa en las provincias y prensa en lenguas distintas al español.

\subsection{Prensa generalista privada}

Nos referimos aquí a las publicaciones periodísticas que no estaban explícitamente dedicadas a un tema, sector profesional o grupo poblacional concreto, aunque en la mayoría de los casos la actualidad comercial, económica y política era la que más atención recibía. Eran periódicos creados por iniciativa privada, por españoles residentes en Filipinas y filipinos hispanohablantes.

El acceso directo a las colecciones de los periódicos El Comercio, Diario de Avisos, Diario de Manila, El Eco de Panay, El Porvenir de Bisayas, La Libertad, La Lectura Popular, La Oceanía Española y La Opinión, y la información sobre otros periódicos obtenida de catálogos en fuentes secundarias (Retana 1895, Retana 1906, Sabido Aguirre 1955), nos han permitido observar varias características comunes a casi todos los periódicos filipinos del siglo XIX, que podríamos agrupar en esta categoría de prensa generalista.

En cuanto a los aspectos formales y editoriales, en casi todos los casos son periódicos de cuatro páginas ${ }^{12}$, sin divisiones por secciones salvo las dedicadas a informaciones tales como el santoral o efemérides. La última página estaba siempre destinada a anuncios comerciales de las tiendas y negocios de Manila o la ciudad de publicación

\footnotetext{
${ }^{11}$ En 1895 Retana (1895: 18), citando a Díaz Arenas, dice que La Estrella, de 1846, es el primer diario de Filipinas. De todas formas, en su obra de 1906 corrige el error y confirma que La Esperanza fue el primero (1906: 1513).

${ }^{12}$ Aparecerán publicaciones más extensas a finales de siglo.
} 
del periódico. El número de columnas por página varía generalmente entre cuatro y seis. Había tanto noticias como artículos de opinión, pero las primeras eran mucho más breves que los segundos. Normalmente cada noticia ocupa apenas unas líneas, en ocasiones tan solo unas decenas de palabras, y se limita a una concisa expresión de los hechos acaecidos en un lenguaje directo, mientras que los artículos de opinión y análisis de la actualidad se extienden mucho más, llegando a veces a ocupar varias columnas e incluso más de una página completa.

Además de la extensión, contrasta también el lenguaje utilizado, que en estos editoriales y artículos de opinión hace uso de frases más largas y estructuras sintácticas complejas para desplegar un lenguaje más literario, elaborado y adornado con recursos estilísticos. Hay también un abundante uso de la ironía, la sátira y el sarcasmo, a menudo destinados a criticar los estilos de vida de los nativos filipinos y de la propia comunidad española. Abundan las alusiones personales, a menudo peyorativas, así como acusaciones, contra los redactores de otros periódicos y contra personajes célebres de la vida social manilense de la época.

Por último, con respecto a los contenidos también existen similitudes en los temas más frecuentemente tratados en los diversos diarios. En los primeros años se usaban principalmente noticias que venían de España o de México, a menudo copiadas directamente de otros diarios citando la fuente, por lo que había muchas más noticias internacionales que locales. Con el tiempo, según se desarrollaba la escena periodística, fueron apareciendo más noticias de sucesos locales como consecuencia de la labor reporteril de los responsables de los periódicos, aunque se incluían también noticias de sucesos de escasa importancia acaecidos en ciudades de España, lo que muestra la dependencia que seguía existiendo de las noticias que pudiesen extraerse de los periódicos llegados de la Península. Las noticias más frecuentes sobre Filipinas eran las relacionadas con las guerras que el ejército español libraba contra los musulmanes en la isla de Mindanao y el archipiélago de Joló, en los límites sureños de las Filipinas, y las internacionales se referían sobre todo a España y Europa, especialmente en los momentos más convulsos que sufrieron a nivel político y social a lo largo del XIX. Hacia el final del siglo cada vez se presta más atención a Asia, con un seguimiento muy cercano a los asuntos de otros territorios coloniales del Sudeste Asiático, como las Indias Orientales Neerlandesas y Malasia, y de la Primera Guerra Sino-japonesa en 1895 y 1896. A finales de siglo algún periódico importante llegó a tener un corresponsal en el exterior, en Hong Kong o Singapur, e incluso en el caso de El Comercio ${ }^{13}$ y La Voz Española, en Madrid.

\footnotetext{
${ }^{13}$ El Comercio fue el periódico más duradero y durante muchos años el más vendido. Nacido el 11 de octubre de 1869, y sobrevivió hasta su fusión con La Opinión en 1926 (Checa Godoy, 2015: 41). Retana cuenta que era el periódico que contaba con más suscriptores, que tenía corresponsal en Madrid y que inauguró el servicio telegráfico desde la capital peninsular en 1888, además de destacar que se
} 
En cuanto a las noticias locales, predominan las comerciales o económicas. Las noticias más frecuentes son las referidas a los movimientos mercantiles: llegadas de barcos al puerto de Manila con información de su carga, la apertura de nuevos mercados, información sobre las aduanas, datos de precios de materias primas y manufacturas, noticias de bancos y productos financieros, etcétera, así como noticias sobre nuevas legislaciones reguladoras de la actividad económica y la reproducción de su articulado.

Los enfrentamientos ideológicos que dieron comienzo con la primera generación de periódicos en los años 1820 continuaron existiendo a lo largo del siglo. Cal lo ilustra en su trabajo sobre El Resumen, en referencia a uno de los temas más discutidos: “...llegando a originar dos bandos en la prensa de Manila, por una parte estarán El Resumen, La Oceanía Española y El Eco de Filipinas defendiendo la representación en Cortes; y en el otro bando se alinearán La Voz Española, Diario de Manila, Boletín de Cebú y El Porvenir de Bisayas" (1999: 38).

Además de informar, estas publicaciones tenían la intención de entretener y divertir. Esto se deduce del tono irónico de muchos artículos, y de la inclusión entre las noticias de muy breves relatos ficticios de sucesos o conversaciones de tono humorístico. Es frecuente encontrar también noticias o reseñas escritas en verso, y a veces la reproducción de relatos literarios e incluso novelas completas por entregas, integradas en el cuerpo del periódico.

A pesar de estos rasgos comunes, hubo periódicos que introdujeron alguna característica distintiva, o que destacaron por prestar más atención hacia ciertos temas aun siendo periódicos generalistas. A modo de ejemplo, el diario La Oceanía Española (1877-1898) dedicaba mucho espacio a tratar asuntos coloniales y la relación de España con sus colonias. En 1885 hizo un profundo seguimiento del proceso de colonización del Golfo de Guinea y de las reclamaciones territoriales en Sáhara Occidental ${ }^{14}$.

Hubo también dos periódicos dedicados a Filipinas pero redactados y publicados en Madrid, que se vendían en ambos territorios: España en Filipinas, semanario publicado desde marzo de 1887, probablemente a propósito de la Exposición de Filipinas celebrada ese año en Madrid, y La Política de España en Filipinas, bisemanario de doce páginas y carácter más académico publicado desde 1891 por periodistas españoles retornados de Filipinas, con especial atención a la divulgación y reflexión sobre temas de historia y colonialismo. Este último periódico abogaba abiertamente por una mayor implicación de las autoridades españolas en la colonización española de las Filipinas

distinguía por su profesionalidad y por abstenerse de incurrir en los frecuentes enfrentamientos que otros periódicos mantenían entre sí (1906: 1557-1559) (1895: 146-152). ${ }^{14}$ Estuvo al frente de esta publicación José Felipe del Pan, hasta su fallecimiento en 1891 . Fue un
periodista, escritor e intelectual español de los más reconocidos en las Filipinas del siglo XIX. 
con el envío de más españoles y la mejora de las condiciones de vida de los que ya vivían allí, los cuales expresaban sus quejas y peticiones a través de cartas que enviaban al periódico y éste publicaba.

\subsection{Prensa oficial}

Algunos periódicos fueron creados por las autoridades administrativas coloniales con el objetivo de ser usados como órganos de comunicación gubernamental para la ciudadanía. Estaban dedicados a la divulgación de nuevas legislaciones, regulaciones, nombramientos, estadísticas poblacionales, sentencias judiciales, y otras informaciones que se considerasen de interés. Carecían de anuncios comerciales, de noticias de sucesos y de cualquier tipo de información no oficial, y tampoco expresaban ninguna valoración subjetiva, opinión ni línea de pensamiento. Incluían también informes sobre el estado de planes de desarrollo a largo plazo, como la construcción de redes de comunicación terrestre o la implementación del sistema escolar público impulsado en los años 1860. También hubo periódicos oficiales destinados a los miembros del ejército, con informaciones de interés para este colectivo.

De los destinados a la población general, el más importante y duradero fue Gaceta de Manila, continuador del Boletín Oficial de Filipinas, que empezó a publicarse en 1852. Gaceta de Manila se mantuvo desde su nacimiento en 1861 hasta el fin de la soberanía española en Filipinas, siendo su último número el del 8 de agosto de 1898. Era diario, de cuatro páginas, sin anuncios comerciales, y contenía el articulado de nuevos reglamentos y legislaciones sobre cualquier tema que afectase a los residentes en Filipinas, fueran españoles o nativos, así como avisos oficiales.

\subsection{Publicaciones especializadas}

La expansión de la oferta periodística en las últimas décadas del siglo se reflejó también en la aparición de multitud de publicaciones dirigidas a gremios profesionales, actividades de ocio o sectores poblacionales específicos. Surgieron, por ejemplo, prensa religiosa, médica, literaria, mercantil, etcétera.

Entre las publicaciones profesionales podemos señalar algunas de legislación y jurisprudencia. El Faro Jurídico nació en 1883, El Consultor de los Jueces de Paz y Gaceta Notarial en 1889, y el año 1894 traería El Consultor de los Municipios y La Legislación. Desde 1892, y aunque por breve tiempo en ambos casos, el funcionariado veía sus intereses profesionales recogidos en el quincenario El Faro Administrativo, y los maestros en El Consultor del Profesorado. Éstos disfrutarían de una publicación de 
mayor duración y entidad a partir de 1895, el Boletín Oficial del Magisterio Filipino. Los profesionales de la sanidad también tuvieron sus propias publicaciones, como el Boletín de Medicina y la Revista de Medicina y Farmacia, ambas de 1886 y efímeras, o las surgidas en 1896 Revista Farmacéutica de Filipinas y Correspondencia Médica de Filipinas. Evidentemente, los sectores económicos más importantes, el comercio y la agricultura, también tuvieron sus publicaciones especializadas. La información comercial y mercantil, aunque muy presente en la prensa generalista, era el tema central de publicaciones como el Boletín de la Cámara de Comercio de Filipinas (1889) y la Revista Mercantil de Filipinas (1892). Con respecto a la agricultura, podemos citar como ejemplos, los Anales de Agricultura e Industrias Derivadas (1889) y el Boletín Oficial Agrícola de Filipinas (1894).

Aparte de las profesionales, también hubo publicaciones destinadas a públicos cuyos intereses peculiares habían estado poco reflejados en la prensa hasta entonces, por ejemplo, al público femenino. La primera fue el semanario ilustrado El Sexo Bello, en 1891. Dos años después apareció la primera publicación periodística escrita por mujeres, también semanal y llamada El Hogar. Ambas tuvieron una breve existencia. También hubo publicaciones destinadas al público infantil y juvenil, como El Liliputiense (1890).

El clero, que constituía un grupo de gran importancia por su número y su influencia, tuvo también publicaciones propias, aunque escasas. En opinión de Sabido Aguirre,

"parece una paradoja que hayan existido muy pocas publicaciones religiosas Filipinas (sic) cuando el fin primordial de la colonización fue propagar la fe, y cuando los mismos misioneros fueron quienes habían enseñado el arte de la imprenta. Establecieron escuelas y colegios, pero se mostraron tardos en extender la influencia del púlpito con la prensa" (1955: 135).

La publicación clerical más importante fue el Boletín Eclesiástico del Arzobispado de Manila (1876) y hubo otras dedicadas a la propagación de la doctrina e ideas católicas, como El Católico Filipino (1862), el diario Regeneración (1886), la Revista Católica de Filipinas (1888) y Apostolado de la Prensa (1894). El estamento militar también usó la prensa como medio de compartir y difundir sus intereses e inquietudes, en publicaciones como la Revista del Ejército y la Armada de Filipinas (1884) ${ }^{15}$, el semanario ilustrado El Ejército de Filipinas, nacido en 1892 y que dos años después se transformó en el diario El Heraldo Militar.

Abundaron las revistas satíricas y humorísticas, con caricaturas gráficas y frecuentes problemas con la censura. Algunos títulos, todos de las décadas de 1880 y 1890, fueron Todo en Broma y La Pavera, de 1892, los semanarios La Semana Elegante

\footnotetext{
${ }^{15}$ Existe cierta confusión sobre la primera publicación militar, en cuanto a título y fecha. Véase Retana (1906: 1610-1615).
} 
(1884), Manila Alegre (1885), Manililla (1887), El Caneco (1890), El Asuang (1891), El Pájaro Verde, La Semana, El Cínife (1894), El Cometa y El Bejuco, ambos de 1898. Otras publicaciones estaban dedicadas al ocio y los entretenimientos, por ejemplo, La Linterna Ecuestre (1881), dedicada al mundo de la equitación, La Puya (1885) ${ }^{16}$, única revista filipina dedicada a la tauromaquia y que apenas llegó a sacar dos números ${ }^{17}$. Manililla-sport fue la única revista sobre deportes, dedicando a uno diferente cada uno de los siete números que publicó en 1894, e incluso el mundo de la moda encontró su espacio con la revista ilustrada La Moda Filipina (1893).

Aunque sin estar especializada en un tema concreto, incluimos en esta sección Ilustración Filipina, por ser una revista de carácter académico y muy mencionada en la literatura por su alta calidad, comparada con similares publicaciones europeas de la época. Se publicó quincenalmente entre marzo de 1859 y diciembre de $1860^{18}$. Fue la primera publicación que incluyó ilustraciones, y en ella multitud de autores contribuyeron artículos gratuitamente según su especialidad, en materias tales como etnografía, ciencias naturales, obras públicas, etcétera. Los editores anunciaron en la presentación de esta revista que su intención era corregir la distorsionada imagen de Filipinas difundida hasta entonces en libros de viajes. Otras revistas dedicadas a las artes y las ciencias fueron, por ejemplo, Revista de Filipinas (1875), muy similar a Ilustración Filipina en cuanto a áreas de conocimiento y también con foco en Filipinas, Revista Filipina de Ciencias y Artes (1882) y La Alhambra (1889).

\subsection{La prensa en las provincias}

Aunque casi toda la actividad periodística estuvo centrada en Manila, también aparecieron publicaciones en otras zonas del archipiélago en las que existían núcleos de residentes españoles. El primero fue el semanario El Eco de Vigan, publicado en esa ciudad de la región de llocos. Su primer número está fechado el 6 de enero de 1884 y se mantuvo hasta diciembre del mismo año. El segundo periódico fuera de Manila se publicó en la ciudad de lloilo, en la isla de Panay, bajo el nombre El Porvenir de Bisayas, también en 1884 . Sobrevivió hasta 1898 y una prueba de su éxito fue el progresivo incremento de su frecuencia, de dos números semanales hasta convertirse en diario. Idéntica evolución tuvo El Eco de Panay, periódico aparecido en la misma ciudad a finales de 1886. Estos dos periódicos protagonizaron el que, según Retana, fue el más aguerrido enfrentamiento vivido en la prensa en Filipinas: "se odiaron de muerte, y no

\footnotetext{
${ }^{16}$ Hubo otra publicación titulada La Puya, que apareció en 1892 y nada tiene que ver con ésta. Era generalista y llevaba por subtítulo "Periódico de asuntos puramente filipinos".

${ }^{17}$ En 1890 se publicó un único número de La Peña, también de temática taurina, pero no tuvo intención de convertirse en publicación regular. Puede verse comentada por Retana (1906: 1678).

${ }^{18}$ No debemos confundir esta publicación con otra que apareció en 1891 con el título La llustración Filipina.
} 
hay en el Periodismo Filipino ejemplo de contiendas más ruidosas que las que sostuvieron los mencionados papeles, que ni un solo día se profesaron mutua consideración" (1906: 1613). El Eco de Panay, de todos modos, es el cuarto de los periódicos aparecidos en provincias. El tercer lugar, por orden cronológico de aparición, corresponde a El Boletín de Cebú, que se publicó semanalmente en esa ciudad de 1886 a 1898. En la ciudad de Nueva Cáceres también se publicó un periódico, entre 1893 y 1894, titulado El Eco del Sur.

Taylor, tras comentar los cuatro primeros periódicos, nos dice que "este periodo marcó el comienzo del periodismo en las provincias. En cuarenta años desde entonces no ha habido prácticamente ningún progreso" (1927: 22), y se queja de la escasa calidad y tirada de los veinticinco o treinta periódicos existentes en las provincias en 1927, exceptuando algunos periódicos de los misioneros cuya calidad destaca.

\subsection{Publicaciones bilingües y en otras lenguas}

El primer periódico que introdujo contenidos en otras lenguas distintas a la castellana fue El Pasig, cuyo primer número data del 13 de julio de 1862 y que mantuvo una frecuencia quincenal. Probablemente perduró tan solo hasta enero del año siguiente (Retana, 1906: 1545). Aunque estaba redactado casi en su totalidad en español, algunos anuncios y artículos aparecían en versión bilingüe, en español y alguna lengua filipina, sobre todo en tagalo.

No fue hasta el uno de junio de 1882, veinte años después, que apareció un periódico enteramente bilingüe, en español y en tagalo. Fue el Diariong Tagalog, dirigido por Francisco Calvo y Muñoz, un alto funcionario español defensor de la concesión de representación parlamentaria a Filipinas en las Cortes Españolas. Duró apenas unos meses. En lengua distinta al tagalo nació El llocano, quincenario en español e ilocano que se mantuvo desde junio de 1889 hasta 1896. Fundado por Isabelo de los Reyes ${ }^{19}$, tenía un carácter instructivo destinado al pueblo ilocano y canalizador de las incipientes aspiraciones políticas de los filipinos.

Otro periódico destacable, también impulsado por Isabelo de los Reyes, es La Lectura Popular (1890- ¿1892?). Bilingüe en español y tagalo, primero fue bisemanal y después semanal $^{20}$. Nació, como indica el primer número (3 de enero de 1890), con ánimo de

\footnotetext{
${ }^{19}$ Isabelo de los Reyes (1864-1938) fue un periodista, escritor, sindicalista y político filipino, figura importante del movimiento nacionalista, tanto bajo la administración española como bajo la estadounidense.

${ }^{20}$ Hubo dos semanarios anteriores, La España Oriental y Revista Católica de Filipinas, que nacieron en 1888 solamente en español y más adelante crearon una versión bilingüe en español y tagalo. De todos modos, según explica Retana (1906: 1642), ambos cedieron su versión bilingüe en 1889 en favor de La Lectura Popular. Aparentemente tuvo más éxito que sus predecesores, llegando a alcanzar una tirada de 4000 ejemplares.
} 
"llenar más perfectamente las necesidades y aspiraciones del pueblo indígena". El análisis de sus contenidos muestra preocupación por los asuntos indígenas, con muchos artículos destinados a informarles sobre sus derechos y obligaciones, y el modo de dirigirse a las autoridades españolas. Pretendía también contribuir a solucionar el secular problema de la escasa difusión del español entre los filipinos y de las lenguas filipinas entre los españoles no clérigos, con la inclusión de secciones de enseñanza de español y de tagalo, con explicaciones gramaticales, consejos para el aprendizaje de estas lenguas y propuestas de uso de los artículos del periódico como ejercicios de traducción.

El primer periódico escrito enteramente en una lengua filipina, en tagalo, fue el Patnubay Nang Catolico (La Lectura Católica), que apareció en 1890 y del que se desconoce su duración. Su director era un agustino español, Mariano Gil, en colaboración con traductores religiosos filipinos y la participación del famoso periodista filipino Pascual H. Poblete (Cal, 1998: 30). La siguiente publicación enteramente en tagalo fue el semanario Ang Pliegong Tagalog (El Pliego Tagalo), cuyo primer número se publicó en mayo de 1896, poco antes del comienzo de la Revolución Filipina, como respuesta a la desaparición de los periódicos bilingües La Lectura Popular y Revista Católica. Fue ya en 1898, año de la independencia de España, cuando aparecieron los primeros periódicos en lengua inglesa, Official Gazette (prensa oficial), The American Soldier, The Manila Times y The Cable News.

\section{Cómputo de periódicos en el siglo XIX}

En base a las fuentes empleadas en este trabajo, hemos llegado a contabilizar 178 publicaciones periodísticas aparecidas en Filipinas hasta $1898^{21}$.

La siguiente gráfica muestra la distribución temporal de las publicaciones:

\footnotetext{
${ }^{21}$ No es posible confirmar la exactitud de este dato, puesto que las propias fuentes utilizadas muestran contradicciones y se han incluido algunas referencias que ofrecen dudas. Se han contabilizado solamente los periódicos en español y los pocos que hubo bilingües en español y otra lengua, dejando fuera los dos periódicos en tagalo que aparecieron en 1890 y 1896.
} 


\section{Nuevas publicaciones periodísticas por décadas en el siglo XIX}

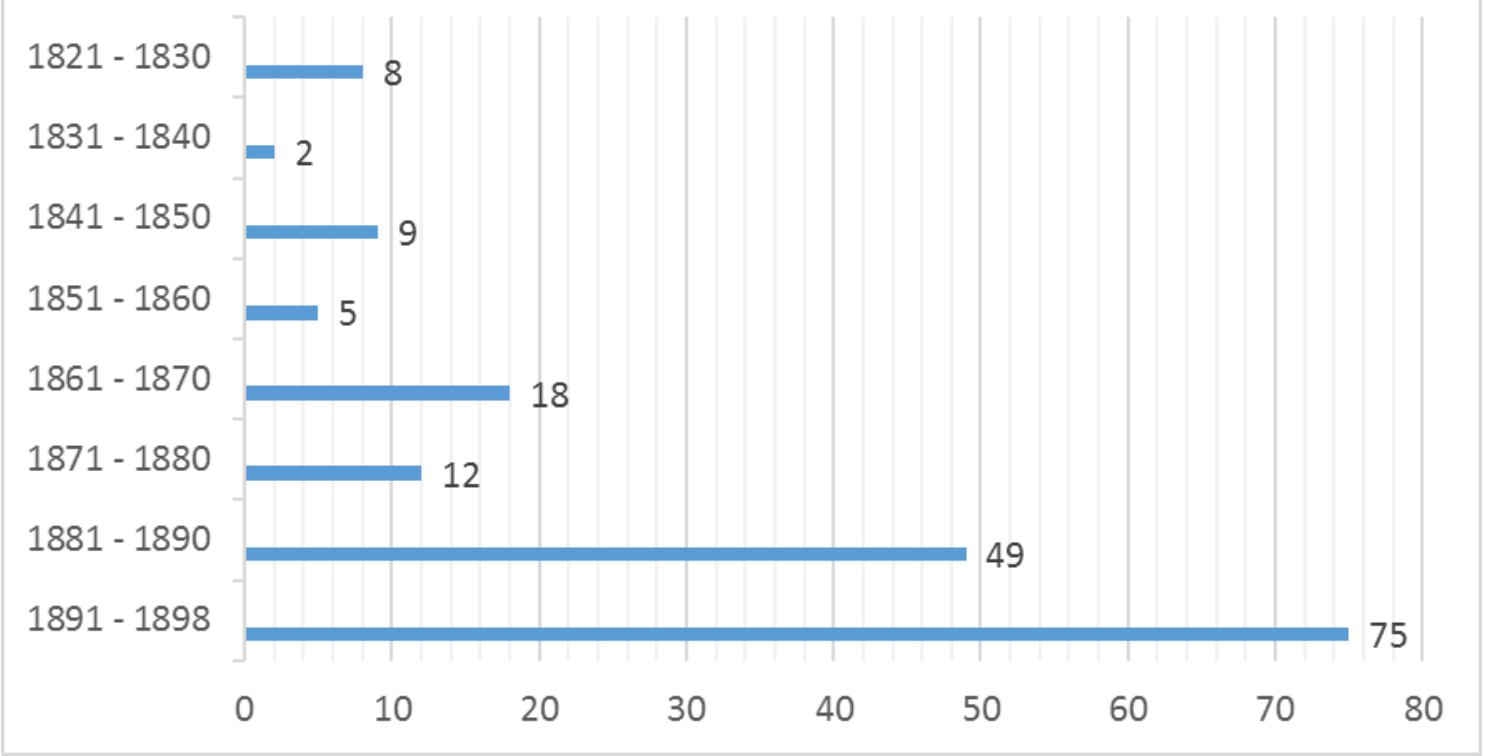

Se observa un marcado aumento en las dos últimas décadas, especialmente en la última teniendo en cuenta que en ese tramo solamente contamos ocho años y que en dos de ellos (mediados de 1896 a mediados de 1898) la guerra desatada por la Revolución Filipina paralizó la materialización de nuevos proyectos ${ }^{22}$.

Varias razones pueden explicar este aumento de la producción periodística en las últimas dos décadas. En primer lugar, la apertura del Canal de Suez en 1869 acortó el viaje entre España y Filipinas, e hizo que se estableciesen relaciones comerciales directas (no a través de México) y que aumentase el flujo de noticias, de ideas, de inversión y de migrantes peninsulares hacia Filipinas. Por otro lado, como señala Sabido Aguirre, entre 1880 y 1896 la aparición de nuevos inventos y tecnologías, como el telégrafo y el tren, y desarrollos sociales como la instrucción pública universal, fueron a la vez fuente de nuevas noticias y potenciadores de su demanda y propagación (1955: 90). Por último, en parte como consecuencia de ese nuevo sistema educativo, surgieron grupos de filipinos instruidos e hispanohablantes que exigían reformas políticas y vieron en la prensa un método de difundir sus anhelos y presionar por su consecución, demandando más noticias y creando sus propios periódicos.

\footnotetext{
${ }^{22}$ En la década de 1880 el número de nuevas publicaciones se mantiene entre una y siete al año, y a partir de 1890 ese número empieza a ser superior a diez, exceptuando 1891 y los años de 1896 y 1897.
} 


\section{La prensa y el nacionalismo filipino}

En 1896 comenzó la Revolución Filipina, que trajo un enfrentamiento bélico entre España y los rebeldes filipinos que aspiraban a la independencia y que se organizaban en torno a la sociedad clandestina independentista conocida como Katipunan, escisión de la anterior Liga Filipina (1892), menos rupturista y más reformista, que perseguía sus objetivos políticos por medios pacíficos. La Liga Filipina estaba formada por filipinos de alto nivel educativo, hispanohablantes, que tenían muchos contactos en España por sus propias estancias de estudios o profesionales en la metrópoli. La Solidaridad es el periódico que fundaron los residentes en España como órgano de expresión del movimiento, y que se publicaba cada dos semanas, enteramente en español. Este periódico se considera un hito en el surgimiento del movimiento nacionalista filipino, y en él escribieron varios de los personajes principales de este movimiento que hoy son considerados héroes de la patria en Filipinas, como José Rizal - Marcelo Hilario del Pilar. Este último ya había contribuido a Diariong Tagalog en 1882. Solidaridad es, probablemente, el periódico del periodo español más mencionado en la historiografía filipina actual. Su primer número vio la luz el 15 de febrero de 1889 en Barcelona -donde se publicó hasta su traslado a Madrid en 1890- y en él anunciaba sus intenciones; promover reformas que mejorasen las condiciones de vida de los filipinos, igualar sus derechos a los de los españoles $y$, sobre todo, tener representación en las Cortes Españolas. Su último número es del 15 de noviembre de 1895. Su lectura revela un tono conciliador en sus comienzos, de humilde petición de reformas, pero puede observarse una progresiva radicalización, con demandas cada vez más rupturistas y una hostilidad muy pronunciada hacia el clero español en Filipinas, al que considera brutal y responsable de todos los males de los filipinos.

El Katipunan también creó su propio periódico, que en consonancia con su posicionamiento se redactó en tagalo. Su título fue Ang Kalayaan. Debido a que se trataba de una organización clandestina y a las dificultades derivadas de tal situación tan solo lograron publicar un número, que se distribuyó alrededor de marzo de 1896 y en el que figuraba como lugar de publicación la ciudad japonesa de Yokohama, en un intento de despistar a las autoridades españolas que resultó inútil porque éstas encontraron su imprenta en Manila cuando se ultimaba el segundo número.

Tras la proclamación de independencia de Filipinas, el 12 de junio de 1898, aparecieron más periódicos de corte nacionalista, escritos en español. El primero de ellos fue La Libertad, primer periódico de la independencia, de marcado carácter nacionalista. Su primer número corresponde al 20 de junio de 1898, apenas una semana después de la proclamación, y fue publicado en la ciudad de Malabón, cercana a Manila ${ }^{23}$. Por decreto de 4 de julio de 1898 del líder revolucionario Emilio Aguinaldo,

\footnotetext{
${ }^{23}$ Este periódico no aparece en los catálogos y monografías utilizados en este trabajo, pero su primer número, con anotaciones manuscritas de su fundador, Clemente J. Zulueta, se encuentra en la
} 
nació el periódico oficial del nuevo gobierno filipino, llamado El Heraldo de la Revolución Filipina, que cambió después varias veces de nombre hasta quedarse con el de Gaceta de Filipinas. Tuvo gran relevancia el diario La Independencia, cuyo primer número apareció el 3 de septiembre de ese mismo año. Fue creado utilizando una imprenta requisada a los frailes agustinos, también en Malabón. No era tan beligerante contra España como contra el clero español, al igual que La Solidaridad, y ensalzó y promovió la figura del entonces ya fallecido José Rizal. En los primeros números muestra simpatías hacia EE.UU., quizás en agradecimiento por la ayuda prestada para independizarse de España y sin saber que pronto se convertiría en la nueva potencia colonial. Retana sospecha que este diario fue cerrado, a principios de 1899, por la intolerancia de la nueva autoridad estadounidense hacia las expresiones de nacionalismo filipino (1906: 1771). Igual suerte le atribuye Retana a otro diario nacionalista análogo, La República Filipina, que había visto la luz el 15 de septiembre de 1898 (ibíd.: 1771-1774). También El Renacimiento, nacido en 1901 y que jugó un importante papel en esos años, fue forzado al cierre por las autoridades estadounidenses debido a su actitud crítica (Teodoro; 1998, p,32) ${ }^{24}$. Otros periódicos nacionalistas en español fueron La Revolución o La Oportunidad, de 1898 y $1899^{25}$.

El cambio de soberanía no supuso un cambio radical en cuanto a la lengua predominante en la prensa. En el año 1899 aparecieron veinticuatro periódicos según el catálogo de Retana (1906: 1784-1791): doce en español, tres bilingües en español y otra lengua, cinco en inglés y cuatro en tagalo.

En el siglo XX siguieron apareciendo muchos periódicos en español, tanto de filipinos hispanohablantes como de la colonia española que permaneció, a pesar de la campaña en contra del uso de la lengua española emprendida por las nuevas autoridades coloniales estadounidenses. Checa Godoy ha contabilizado en el periodo comprendido entre 1898 y 1941 "por encima de los 220 títulos en español, de ellos más de 30 diarios, con una rica prensa regional, además de un número cercano de títulos redactados en dos o incluso tres idiomas, con el español entre ellos" (2015: 23). El número de publicaciones periodísticas en inglés aumentó exponencialmente, así como el de lenguas filipinas, e incluso aparecieron algunas en chino ${ }^{26}$, pero a pesar de ello la

hemeroteca microfilmada de la Universidad Ateneo de Manila. Una anotación en la portada reza "Este es el primer periódico de la revolución. Se suspendió por intrigas en la camarilla de Aguinaldo. Estaba dirigido por mí y se publicó en Malabón (Tambobong)".

${ }^{24}$ Para un detallado análisis de la historia de El Renacimiento y la censura sobre el periodismo nacionalista en estos años de transición, véase Cano, G. (2011): “Filipino Press between Two Empires: El Renacimiento, a Newspaper with Too Much Alma Filipina" en Southeast Asian Studies, Vol. 49, n. 3, 2011, pp. 395-430.

${ }^{25}$ La obra de Taylor (1927) citada anteriormente incluye a modo de epílogo un artículo de Epifanio de los Santos titulado The Philippine Revolutionary Press, con un listado e información sobre la prensa en estos dos años.

${ }^{26}$ El primer periódico chino fue Kong Li Po (1912), al que siguieron varios más (Fernandez, 1989: 327). 
prensa en español siguió dominando la escena periodística filipina durante las dos primeras décadas del siglo XX, sobre todo en cuanto a los diarios generalistas. En 1910 apareció el periódico El Ideal, uno de los más importantes del siglo XX en español. El subtítulo era "Órgano del Partido Nacionalista", en referencia al Partido Nacionalista Filipino creado por Sergio Osmeña en $1907^{27}$. El hecho de que fuera publicado en español en vez de en tagalo muestra hasta qué punto el español había llegado a ser considerado por los filipinos como una lengua propia y de unidad de la nueva nación filipina, lo que había quedado también reflejado en la elección del español para la redacción de la primera constitución y el himno nacional en 1899.

En los años 1920 y 1930 el número de periódicos en español y su tirada fueron disminuyendo, mientras aumentaba la presencia de prensa en inglés y lenguas autóctonas, sobre todo tagalo, llegando a desbancar al español de su posición dominante. La prensa en español seguiría una constante decadencia que se agravó mucho por la II Guerra Mundial, tras la cual ya fue marginal.

\section{Conclusiones}

La existencia de ciertas condiciones desfavorables, como la lejanía de la metrópoli, la escasa presencia de hispanohablantes y la limitada penetración de la lengua española, no impidió el desarrollo de una rica y variada escena periodística en las Filipinas del siglo XIX. Otros problemas como la censura y la falta de medios técnicos fueron superados por el ingenio y empeño de los pioneros de la prensa filipina, a pesar de que la mayoría de las publicaciones tenían una vida efímera por falta de planificación o de suscriptores. La existencia de censura de prensa no supuso un inconveniente importante, según se deduce por las escasas referencias a publicaciones que sufriesen dificultades en ese sentido.

En las primeras décadas se dependía de la llegada de noticias desde España o México, pero a partir de los años 1840 empezaron a surgir periódicos capaces de generar contenidos de manera independiente. Al mismo tiempo comenzaron las luchas ideológicas entre periódicos, que se mantendrían durante todo el siglo y son muestra de relativa libertad de prensa.

Los temas más tratados en la prensa generalista guardaban relación principalmente con los intereses económicos de la comunidad española, la administración de la

\footnotetext{
${ }^{27}$ Sergio Osmeña fue vicepresidente de la primera presidencia filipina y posteriormente presidente, durante los dos últimos años del periodo de la Mancomunidad Filipina (1935-1946). El Partido Nacionalista Filipino ha mantenido su existencia hasta el día de hoy, en que bajo el nombre de Nacionalista Party es el más antiguo de los partidos políticos filipinos.
} 
colonia y los cambios políticos en España, aunque generalmente predominaban las noticias internacionales sobre las locales. Hacia el final de siglo otros temas como la situación política de los vecinos asiáticos también cobraron cierto protagonismo. Aparte de las noticias, los periódicos incluían editoriales muy extensos y elaborados, frecuentemente con alusiones personales y tono sarcástico, así como contenidos literarios.

En las dos últimas décadas del siglo se disparó el número de publicaciones, y surgieron periódicos y revistas dirigidas a intereses profesionales y culturales específicos, y a diversos grupos poblacionales, así como multitud de publicaciones humorísticas.

En el año 1898 y en los siguientes empezaron a aparecer periódicos en inglés y aumentó el número de los de lenguas filipinas, aunque el español siguió siendo la lengua más usada en la prensa hasta la tercera década del siglo XX. A partir de entonces comenzó su declive hasta que los devastadores efectos de la Segunda Guerra Mundial prácticamente acabaron con la prensa en español y con la esperanza de conservación del idioma. A pesar de ello Filipinas y España han quedado para siempre hermanadas por una historia común que está plasmada, entre otros muchos lugares, en la prensa del siglo XIX.

\section{Referencias bibliográficas}

ALONSO ÁlVAREZ, L., HIDALGO NUCHERA, P. (2000): “Los nietos de Legazpi revisan el pasado. Continuidad y cambio en los estudios históricos filipinistas en España, 1950-1998" en Illes i Imperis, no 3, primavera 2000, pp. 23-59.

ARTIGAS y CUERVA, M. (1909): Los periódicos filipinos: la más completa bibliografía publicada hasta la fecha acerca de los papeles públicos filipinos, Manila, Biblioteca Nacional Filipina.

CAL, R. (1998): "Propaganda revolucionaria en Filipinas: el Resumen y la Liga Filipina" en Historia y Comunicación Social, no 3, 1998, pp. 27-39.

(1999): “Filipinas 1898: el control de la prensa" en Investigaciones Históricas: Época Moderna y Contemporánea, №19, 1999, 159-168.

CANO, G. (2011): "La Solidaridad y el periodismo en Filipinas en tiempos de Rizal” en VV. AA., Entre España y Filipinas: José Rizal, escritor, Madrid, MAEC, pp. 171-201. 
Nacimiento y evolución de la prensa en Filipinas en el siglo XIX: de los intereses españoles al nacionalismo filipino

Census of the Philippine Islands. Taken under the Direction of the Philippine Commission in the year 1903, Washington, United States Bureau of the Census, 1905.

CHECA GODOY, A. (2015): "La prensa filipina en español entre dos guerras (18991941)" en Revista Internacional de Historia de la Comunicación, no 4, Vol.1, 2015, pp. 22-51.

FERNANDEZ, D. G. (1989): “The Philippine Press System: 1811-1989" en Philippine Studies, no 37, 1989, pp. 317-344.

GARCÍA-ABÁSOLO, A. (2011): "Los chinos y el modelo colonial español en Filipinas" en Cuadernos de Historia Moderna, X, 2011, pp. 223-242.

GARCÍA de los ARCOS, M. F. (2000): "La cultura española en Filipinas: 1565-1898" en Cabrero, L. (coord.), Historia general de Filipinas, Madrid, Ediciones de Cultura Hispánica, pp. 401-445.

GONZÁLEZ FERNÁNDEZ, R. (1877): Anuario filipino para 1877, Manila, Establecimiento tipográfico de Plana y $C$ a.

MOYA y JIMÉNEZ, F. J. de (1883): Las Islas Filipinas en 1882. Estudios históricos, geográficos, estadísticos y descriptivos, Madrid, Establecimiento tipográfico de El Correo.

ORTIZ ARMENGOL, P. (2000): "La modernidad y la inquietud política en el siglo XIX" en Cabrero, L. (coord.), Historia general de Filipinas, Madrid, Ediciones de Cultura Hispánica, pp. 293-337.

RETANA, W. E. (1895): El periodismo filipino. Noticias para su historia (1811-1894), Madrid, Imprenta de la Viuda de M. Minuesa de los Ríos.

(1906): "El Periodismo Filipino" en Retana, W. E.: Aparato bibliográfico de la Historia general de Filipinas, deducido de la colección que posee en Barcelona la Compañía General de Tabacos de dichas islas, Volumen 3, Madrid, Imprenta de la Sucesora de M. Minuesa de los Ríos, pp. 1493-1800.

(1907): "La censura de imprenta en Filipinas" en Nuestro Tiempo, VII, n.107, 1907, pp. 192-231.

SABIDO AGUIRRE, L. (1955): El periodismo filipino durante la época española, Madrid, Universidad Complutense de Madrid (tesis doctoral).

TAYLOR, C. (1927): History of the Philippine Press, Manila, s.n. 
TEODORO, L. V. (1998): "The Philippine Press: Between Two Traditions" en Teodoro L. V. y De Jesus, M. Q. (editors), The Filipino Press and Media, Democracy and Development, Diliman (Quezon City), University of the Philippines Press, pp. 3135.

VALENZUELA, J. Z. (1933): History of Journalism in the Philippine Islands, Manila, publicado por el autor. 